\title{
Postinfarction Ventricular Septal Rupture - A Rare Complication Remains Challenge for Cardiac Surgical Team
}

\section{Rohn V. ${ }^{1}$, Grus T. ${ }^{1}$, Lindner J. ${ }^{1}$, Lipš M. ${ }^{2}$, Bělohlávek J. ${ }^{3}$}

${ }^{1} 2^{\text {nd }}$ Department of Surgery - Department of Cardiovascular Surgery, First Faculty of Medicine, Charles University in Prague and General University Hospital in Prague, Prague, Czech Republic;

2Department of Anesthesiology and Intensive Care, First Faculty of Medicine, Charles University in Prague and General University Hospital in Prague, Prague, Czech Republic;

${ }^{3} 2^{\text {nd }}$ Department of Medicine - Department of Cardiovascular Medicine, First Faculty of Medicine, Charles University in Prague and General University Hospital in Prague, Prague, Czech Republic

Received July 26, 2012; Accepted January 15, 2013.

Key words: Myocardial infarction - Ventricular septal rupture - Ventricular assist device

Abstract: The incidence of post infarction ventricular septal rupture (PIVSR) is decreasing in the last years due to aggressive treatment of myocardial infarction with early percutaneous coronary interventions. As a consequence patients with PIVSR are referred to surgery more often with significant heart failure. The aim of this retrospective study was to assess the influence of these on the operative results and to identify the risk factors of operative mortality. A retrospective analysis of prospectively collected data of patients with the PIVSR admitted to our center from November 2004 to February 2012 was performed. Variables were analyzed using two-dimensional correspondence analysis. There were 25 patients (12 males and 13 females) with mean age 70.2 years (47-82) operated on; 17 (68\%) presented with anterior and $8(32 \%)$ with posterior PIVSR. Eighteen patients (72\%) had acute heart failure, 13 (52\%) presented with cardiogenic shock. Before surgery, intraaortic balloon pump (IABP) had 20 (80\%) patients; in 4 (16\%) a ventricular assist device was used, either Extracorporeal Membrane Oxygenation (ECMO) or centrifugal pumps as biventricular assist. Operative mortality was 40\% (10 pts.).

Mailing Address: Vilém Rohn, MD., PhD., $2^{\text {nd }}$ Department of Surgery Department of Cardiovascular Surgery, First Faculty of Medicine, Charles University in Prague and General University Hospital in Prague, $U$ nemocnice 2, 12800 Prague 2, Czech Republic; Phone: +420 224962 797; Fax: +420 224922 695; e-mail: vilem.rohn@seznam.cz 
Four patients (12\%) had small non-significant recurrent shunt on postoperative echocardiography. Although majority of patients with PIVSR have significant heart failure prior to surgery the operative mortality remains comparable to older studies. Predictors of perioperative death were concomitant surgical reconstruction of the left ventricle, renal impairment before operation, male gender, history of coronary artery disease, PIVSR location posterior, and shock at surgery.

\section{Introduction}

Post infarction ventricular septal rupture (PIVSR) is a rare but serious complication of myocardial infarction (MI). Its incidence is decreasing due to aggressive treatment of acute MI. In the era before thrombolytic therapy, it was estimated that PIVSR complicates 1-2\% of acute myocardial infarctions (Topaz et al., 1989; Crenshaw et al., 2000). At the present time when acute reperfusion therapy by percutaneous interventions became a routine, the incidence of PIVSR has been estimated about 0.2\% of all infarctions (Crenshaw et al., 2000; Yip et al., 2004).

Medical treatment of PIVSR is usually not efficient (Crenshaw et al., 2000), and early surgical closure of the rupture is recommended (Deja et al., 2000; Labrousse et al., 2002; Yip et al., 2004). However surgical repair is associated with a high rate of mortality even in more recent reports (David et al., 1995; Deja et al., 2000; Labrousse et al., 2002). The most important predictor of operative mortality is preoperative hemodynamic instability.

In this report we analyzed our experience with the treatment of patients with ventricular septal rupture during the last years.

\section{Patients and Methods}

A retrospective analysis of prospectively collected data of all patients admitted to our center from November 2004 to February 2012 with the PIVSR was performed. All patients with acute pulmonary edema, congestive heart failure or hemodynamic instability necessitating i.v. inotropic support were considered to have acute heart failure. Criteria for considering cardiogenic shock were systolic blood pressure $<80 \mathrm{~mm} \mathrm{Hg}$, cardiac index $<2.0 \mathrm{l} / \mathrm{min} / \mathrm{m}^{2}$, base excess $>-8 \mathrm{mEq} / \mathrm{l}$, and urine output less than $30 \mathrm{ml}$ in 1 hour. Hospital mortality was defined as death within 30 days of operation or during the same hospital admission.

\section{Surgical technique}

Surgical repair was performed by slightly modifying technique described by David et al. (1995), with the use of endoventricular patch of autologous glutaraldehydefixed pericardium. All patients were operated on through a median sternotomy, cardiopulmonary bypass was accomplished with bicaval venous drainage; cardiac arrest was achieved with cold, antegrade, blood cardioplegia. Myocardial revascularization was done before the repair of the PIVSR. 


\section{Statistical analysis}

Preoperative, operative and postoperative data were collected on retrospective review of patient's record. All continuous data are expressed as mean and standard deviation. The incidences are presented as percentages.

Variables were analyzed using two-dimensional correspondence analysis and SPSS software.

Variables entered into correspondence analysis are listed in Table 1.

\section{Table 1 - Characteristics of the patients}

\begin{tabular}{|c|c|}
\hline Characteristics, $n=25$ & $\mathrm{~N}(\%)$ or mean $\pm \mathrm{SD}$ \\
\hline \multicolumn{2}{|l|}{ Sex } \\
\hline male & $12(48 \%)$ \\
\hline female & $13(52 \%)$ \\
\hline Age $(y)$ & $70.2(47-82)$ \\
\hline Mean time from Ml to surgery (days) & $4.6 \pm 2.19$ \\
\hline Mean time from rupture to surgery (days) & $1.7 \pm 1.17$ \\
\hline Diabetes & $8(32 \%)$ \\
\hline Hypertension & $16(64 \%)$ \\
\hline Renal dysfunction (serum creatinin more than $200 \mu \mathrm{mol} / \mathrm{l}$ ) & $8(32 \%)$ \\
\hline Dialysis & $1(4 \%)$ \\
\hline Mean serum creatinin $(\mu \mathrm{mol} / \mathrm{l})$ & $174.5 \pm 29.8$ \\
\hline COPD & $4(16 \%)$ \\
\hline Neurologic dysfunction & $2(8 \%)$ \\
\hline Peripheral vascular disease & $9(36 \%)$ \\
\hline Previous $\mathrm{PCl}$ & $13(52 \%)$ \\
\hline Pulmonary artery pressure (syst., $\mathrm{mm} \mathrm{Hg}$ ) & $55 \pm 21.8$ \\
\hline Left ventricular ejection fraction (\%) & $42.8 \pm 12.9$ \\
\hline LV EF less than $30 \%$ & $3(12 \%)$ \\
\hline Mitral valve insufficiency grade 2 or more & $5(20 \%)$ \\
\hline i.v. inotropes & $18(72 \%)$ \\
\hline Posterior ventricular septal rupture & $8(32 \%)$ \\
\hline Cardiogenic shock & $13(52 \%)$ \\
\hline IABP before operation & $20(80 \%)$ \\
\hline Ventricular assist device & $4(16 \%)$ \\
\hline
\end{tabular}

SD - standard deviation; MI - myocardial infarction; COPD - chronic obstructive pulmonary disease;

$\mathrm{PCl}$ - percutaneous coronary interventions; LV EF - left ventricular ejection fraction; IABP - intraaortic balloon pump 


\section{Results}

Between November 2004 and February 2012, 25 patients (12 males and 13 females) were treated in our center with acute PIVSR. Mean age of patients was 70.2 years (from 47 to 82 ). Distribution of risk factors and preoperative characteristic of the cohort shows Table 1.

Eighteen patients (72\%) had acute heart failure necessitating i.v. inotropes. Thirteen patients (52\%) presented with cardiogenic shock. All patients had pulmonary hypertension; mean systolic pulmonary artery pressure was $55 \pm 21.8 \mathrm{~mm}$ of mercury. Mean left ventricular ejection fraction was $42.8 \pm 12.9 \%$; there were 3 patients with ejection fraction below $30 \%$. Intraaortic balloon pump (IABP) was inserted before the operation to $20(80 \%)$ patients. Eight patients (32\%) had posterior PIVSR following an inferoseptal infarction.

Operative data are shown in Table 2. Majority of patients (21, e.g. 84\%) were operated on day of admission to our unit. In $4(16 \%)$ cases we first implanted ventricular assist device; three times Extracorporeal Membrane Oxygenation (PLS ECMO, Maquet, Germany) as a biventricular mechanical assist device and in one case two centrifugal pumps (Biomedicus, Medtronic, USA) as biventricular assist (BiVAD). Those patients we operated later after stabilization of the hemodynamics (Rohn et al., 2009).

Table 2 - Operative data of the patients

\begin{tabular}{lc}
\hline $\mathrm{n}=25$ & mean $\pm \mathrm{SD}$ \\
\hline CPB time (min) & $182 \pm 42.5$ \\
Cross-clamp time (min) & $94.6 \pm 26.55$ \\
& mean $\pm \mathrm{SD}, \mathrm{n}(\%)$ \\
Concomitant procedure & \\
CABG (pts.) & $17(68 \%)$ \\
Distal anastomoses & $1.46 \pm 0.83$ \\
Surgical reconstruction of LV & $5(20 \%)$ \\
\hline
\end{tabular}

CPB - cardiopulmonary bypass time; CABG - coronary artery bypass graft; LV - left ventricle

The time that elapsed from $\mathrm{Ml}$ to surgery and from septal rupture to surgery averaged $4.6 \pm 2.19$ (median 5) and $1.7 \pm 1.17$ days (median 1), respectively.

The mean cross-clamp time was $94.6 \pm 26.55$ minutes. Cardiopulmonary bypass time averaged $182 \pm 42.5$ minutes. Seventeen (68\%) patients had concomitant coronary artery bypass grafting. Mean number of distal coronary anastomoses was $1.46 \pm 0.83$. Mitral valve repair were performed in 3 cases and surgical reconstruction of the left ventricle in 5 . 
The operative mortality (in hospital or within 30 days of operation) was $40 \%$ (10 patients). The most common cause of death was persistent low cardiac output and multiorgan failure.

Seven patients (28\%) had renal failure requiring postoperative dialysis. Mean length of stay in intensive care unit was $8.5 \pm 10.8$ days, while mean length of hospital stay was $11.4 \pm 13.9$ days. Only 1 patient (4\%) had significant neurological dysfunction after PIVSR repair. All patients were controlled by transthoracic or transesofageal echo on daily basis during the first week after surgery (operative results are summarized in Table 3). Four patients (12\%) had small non-significant recurrent ventricular septal defect which was detected on the echo 4-7 days after surgery (Table 4) with the Qp:Qs ratio less than 1.5:1. None of them was re-operated.

Table 3 - Postoperative results

\begin{tabular}{lc}
\hline Events, $\mathrm{n}=25$ & $\mathrm{~N}(\%)$ or mean \pm SD \\
\hline In hospital or 30-day mortality & $10(40 \%)$ \\
Multiorgan failure & $14(56 \%)$ \\
Recurrent ventricular septal defect & $4(12 \%)$ \\
Dialysis & $7(28 \%)$ \\
Neurological dysfunction & $1(4 \%)$ \\
Ventricular fibrillation & $2(8 \%)$ \\
Discharged from hospital & $12(48 \%)$ \\
Length of ICU stay (days) & $8.5 \pm 10.8$ \\
Length of hospital stay after surgery (days) & $11.4 \pm 13.9$ \\
\hline
\end{tabular}

ICU - intensive care unit

The correspondence analysis revealed that the risk factors for hospital death were: concomitant reconstruction of the left ventricle, renal impairment before operation (e.g. serum creatinine level above $200 \mu \mathrm{mol} / \mathrm{l}$ ), male gender, history of coronary artery disease or MI, PIVSR location posterior, and shock at surgery (Table 4).

\section{Discussion}

The incidence of post infarction ventricular septal rupture is very low in the recent era of aggressive treatment of acute myocardial infarctions by early percutaneous interventions; it is estimated about $0.2 \%$ of all infarctions (Crenshaw et al., 2000; Yip et al., 2004). However, it remains one of the most serious complications. The most important determinant of early outcome following post infarction ventricular septal rupture is the development of heart failure (Deville et al., 1991). As the 
Table 4 - Predictors of operative or 30-day mortality. Results of the correspondence analysis

\begin{tabular}{ll}
\hline COPD & 1.54 \\
Use of ECMO & 1.54 \\
Recurrent ventricular septal defect & 1.54 \\
Smoking & 0.32 \\
Hypertension & 0.32 \\
Female & 0.29 \\
\hline IABK/ECMO & 0.20 \\
\hline Concomitant CABG & 0.14 \\
\hline Preoperative IABP & 0.11 \\
\hline Shock on admission & 0.09 \\
\hline Right ventricular failure & -0.09 \\
\hline Diabetes mellitus & -0.09 \\
\hline Shock at surgery & -0.27 \\
\hline History of MI & -0.27 \\
\hline PIVSR location posterior & -0.33 \\
\hline History of previous coronary artery disease & -0.42 \\
\hline Male gender & $-0.64 \quad$ non-survivors \\
\hline Renal impairment (creatinin $>\mathbf{2 0 0} \boldsymbol{\mu m o l} / \mathbf{l})$ & -0.79 \\
\hline Concomitant surgical reconstruction of the & -0.91 \\
\hline left ventricle & \\
\hline & \\
\hline
\end{tabular}

COPD - chronic obstructive pulmonary disease; ECMO - extracorporeal membrane oxygenation; IABK - intraaortic balloon pump; CABG - coronary artery bypass graft; MI - myocardial infarction; PIVSR - post infarction ventricular septal rupture; IABP - intraaortic balloon pump

PIVSR becomes rarer, it seems that the spectrum of operated patients is changing towards patients with heart failure and cardiogenic shock. Deja et al. presented in the year 2000117 patients who underwent postinfarction ventricular septal defect (VSD) repair in a period of 12 years from 1986 through 1998. In their cohort 30\% of patients developed LV failure and $14 \%$ required mechanical ventilation before surgery (Deja et al., 2000). In 2002 Labrousse and colleagues published a series of 101 consecutive patients with post infarction VSD who were operated on between December 1971 and December 2000. Nineteen percent of them presented with cardiogenic shock, defined as a systolic pressure below $70 \mathrm{~mm} \mathrm{Hg}$ with evidence of 
inadequate organ and peripheral perfusion; additional $33 \%$ had low cardiac output and severe congestive heart failure (Labrousse et al., 2002). In our series, there were 18 patients $(72 \%)$ who needed inotropic support before operation due to heart failure, and 13 of them (52\%) were in cardiogenic shock.

This of course is reflected in operative mortality. The 30-day mortality reported by David in 1995 was 19\%, Deja in 2000 reported 35\%, and Labrousse in 2002 reported 42\% in hospital mortality (David et al., 1995; Deja et al., 2000; Labrousse et al., 2002). The overall incidence of early mortality in our series was $40 \%$.

Results of the statistical analysis showed that the risk factors for operative or 30-day mortality in our patient's cohort were: concomitant surgical reconstruction of the left ventricle, renal impairment before operation, male gender, history of coronary artery disease, PIVSR location posterior, and shock at surgery. Surprisingly, right ventricular failure on preoperative echocardiography was not a predictor of perioperative death. This could perhaps be explained by small number of patients, or by extensive use of IABP or other mechanical heart support before operation.

In cases of PIVSR, the use of mechanical circulatory support allows time for the hemodynamic status to stabilize and for the condition of more critically ill patients to improve before surgical repair (Gregoric et al., 2008; Rohn et al., 2009). Other methods have been used to delay surgery and improve hemodynamic status, including temporary closure of a VSD with a Swan-Ganz balloon catheter (Abhyankar and Jagtap, 1999), calibrated sizing balloon (Zanchetta et al., 2003) or Amplatzer occluder (Schiele et al., 2003).

In patients in severe cardiogenic shock, we used preoperatively biventricular assist device (ECMO or biventricular centrifugal pumps) in an effort to maintain cardiac output and arterial pressure to ensure peripheral organ perfusion, to unload ventricles and reduce the left-to-right shunt and to decrease the tension on the septum. We usually left the assist device running several days after surgery and then we weaned the patient off the assist device.

With the progress in treatment of patients with acute MI, cardiac surgeons are facing a new situation, when the patients with PIVSR are much less common. These can cause that the surgeons and all the surgical teams are slowly loosing their skills in treatment of such patients, despite the progress in surgical technique and perioperative care in coronary surgery during last years. On the other hand patients are admitted in worse hemodynamic state and with considerable higher risk of operative mortality. Unsatisfactory results of the surgical treatment of PIVSR led us to change the treatment strategy. In order to improve the surgical results we suggest concentrating all patients with PIVSR in specialized cardiac centers with the access to ventricular assist device. Hemodynamically stable patients should be operated on soon (Deville et al., 1991; David et al., 1995; Labrousse et al., 2002). All patients with acute heart failure or in cardiogenic shock we propose to implant a biventricular assist device and operate on them after improvement of organ 
dysfunction and hemodynamic stabilization. The use of left-ventricular mechanical support alone yield potential risk of high right-to-left shunting across the septum, which may cause hypoxic brain injury (Kshettry et al., 1997).

\section{Conclusion}

The PIVSR is much less common in the recent years. Patients are more often referred to surgery with significant heart failure. The mortality in our study was comparable to previous studies. Predictors of perioperative death were concomitant surgical reconstruction of the left ventricle, renal impairment before operation, male gender, history of coronary artery disease, PIVSR location posterior, and shock at surgery. Right ventricular failure was not identified as risk factors of perioperative death. Concentration of patients with PIVSR to specialized centers and more liberal use of ventricular assist devices preoperatively can lead to improvements of the surgical results.

\section{References}

Abhyankar, A. D., Jagtap, P. M. (1999) Post-infarction ventricular septal defect: percutaneous transvenous temporary closure using a Swan-Ganz catheter. Catheter. Cardiovasc. Interv. 47(2), 208-210.

Crenshaw, B. S., Granger, C. B., Birnbaum, Y., Pieper, K. S., Morris, D. C., Kleiman, N. S., Vahanian, A., Califf, R. M., Topo, E. J. (2000) Risk factors, angiographic patterns, and outcomes in patients with ventricular septal defect complicating acute myocardial infarction. GUSTO-I (Global Utilization of Streptokinase and TPA for Occluded Coronary Arteries) Trial Investigators. Circulation 101(1), 27-32.

David, T. E., Dale, L., Sun, Z. (1995) Postinfarction ventricular septal rupture: repair by endocardial patch with infarct exclusion. J. Thorac. Cardiovasc. Surg. 110, 1315-1322.

Deja, M. A., Szostek, J., Widenka, K., Szafron, B., Spyt, T. J., Hickey, M. S., Sosnowski, A. W. (2000) Post infarction ventricular septal defect - can we do better? Eur. J. Cardiothorac. Surg. 18(2), 194-201.

Deville, C., Fontan, F., Chevalier, J. M., Madonna, F., Ebner, A., Besse, P. (1991) Surgery of post-infarction ventricular defect: risk factors for hospital death and long-term results. Eur. J. Cardiothorac. Surg. 5(4), 167-174.

Gregoric, I. D., Bieniarz, M. C., Arora, H., Frazier, O. H., Kar, B., Loyalka, B. (2008) Percutaneous ventricular assist device support in a patient with a postinfarction ventricular septal defect. Tex. Heart Inst. J. 35(1), 46-49.

Kshettry, V., Salerno, C., Bank, A. (1997) Risk of left ventricular assist device as a bridge to heart transplant following postinfarction ventricular septal rupture. J. Card. Surg. 12, 93-97.

Labrousse, L., Choukroun, E., Chevalier, J. M., Madonna, F., Robertie, F., Merlico, F., Coste, P., Deville, C. (2002) Surgery for post infarction ventricular septal defect (VSD): risk factors for hospital death and long term results. Eur. J. Cardiothorac. Surg. 21, 725-732.

Rohn, V., Spacek, M., Belohlavek, J., Tosovsky, J. (2009) Cardiogenic shock in patient with posterior postinfarction septal rupture - Successful treatment with extracorporeal membrane oxygenation (ECMO) as a ventricular assist device. J. Card. Surg. 24, 435-436.

Schiele, T. M., Kozlik-Friedman, R., Sohn, H. Y., Stempfle, H. U., Küchle, C., Schopohl, J., Thiesen, K., Liebig, M., Klauss, V. (2003) Transcatheter closure of a ruptured ventricular septum following inferior myocardial infarction and cardiogenic shock. Catheter. Cardiovasc. Interv. 60(2), 224-228.

Rohn V.; Grus T.; Lindner J.; Lipš M.; Bělohlávek J. 
Topaz, O., Mallon, S. M., Chanine, R. A., Sequeira, R. F., Myerburg, R. J. (1989) Acute ventricular septal rupture. Angiographic-morphologic features and clinical assessment. Chest 95(2), 292-298.

Yip, H. K., Fang, C. Y., Tsai, K. T., Chang, H. W., Yeh, K. H., Fu, M., Wu, C. J. (2004) The potential impact of primary percutaneous coronary intervention on ventricular septal rupture complicating acute myocardial infarction. Chest 125, 1622-1628.

Zanchetta, M., Pedon, L., Rigatelli, G., Zennaro, M., Maiolino, P. (2003) Transcatheter balloon closure of postmyocardial infarction ventricular septal defect: a bridge to surgery. Int. J. Cardiol. 92(2-3), 297-298. 